\title{
Epidermal-specific deletion of CD44 reveals a function in keratinocytes in response to mechanical stress
}

\author{
M Shatirishvili ${ }^{1}$, AS Burk ${ }^{2,9}$, CM Franz ${ }^{3,9}$, G Pace ${ }^{1}$, T Kastilan ${ }^{1}$, K Breuhahn $^{4}$, E Hinterseer ${ }^{5}$, A Dierich ${ }^{6}$, L Bakiri ${ }^{7}$, EF Wagner ${ }^{7}$, H Ponta ${ }^{1}$, \\ TN Hartmann ${ }^{5}, M_{\text {Tanaka }}{ }^{2,8}$ and V Orian-Rousseau ${ }^{\star, 1}$
}

CD44, a large family of transmembrane glycoproteins, plays decisive roles in physiological and pathological conditions. CD44 isoforms are involved in several signaling pathways essential for life such as growth factor-induced signaling by EGF, HGF or VEGF. CD44 is also the main hyaluronan (HA) receptor and as such is involved in HA-dependent processes. To allow a genetic dissection of CD44 functions in homeostasis and disease, we generated a Cd44 floxed allele allowing tissue- and time-specific inactivation of all CD44 isoforms in vivo. As a proof of principle, we inactivated Cd44 in the skin epidermis using the K14Cre allele. Although the skin of such $C d 44^{\mathrm{ker}}$ mutants appeared morphologically normal, epidermal stiffness was reduced, wound healing delayed and TPA induced epidermal thickening decreased. These phenotypes might be caused by cell autonomous defects in differentiation and HA production as well as impaired adhesion and migration on HA by $\mathrm{Cd} 44^{\Delta \text { ker }}$ keratinocytes. These findings support the usefulness of the conditional Cd44 allele in unraveling essential physiological and pathological functions of CD44 isoforms.

Cell Death and Disease (2016) 7, e2461; doi:10.1038/cddis.2016.342; published online 10 November 2016

CD44 is a large family of transmembrane glycoproteins controlling cell behavior and cell fate (reviewed in ref. 1). The inclusion of different combinations of variant exons in the CD44 extracellular domain gives rise to a plethora of CD44 variant isoforms with distinct extracellular domains. The smallest CD44 isoform, namely CD44s (standard), is devoid of variant exons (reviewed in ref. 1). CD44 isoforms are expressed in many different tissues, CD44s being the predominant form expressed at early stages of embryogenesis. ${ }^{2}$ Accumulating evidence indicate that CD44 is a master regulator of cell signaling. For example, the v3-containing heparan sulphated CD44 isoforms (CD44v3) bind growth factors such as HB-EGF or b-FGF. ${ }^{3}$ During limb development such a specific heparan sulphated isoform is expressed in cells of the apical ectodermal ridge and is involved in the presentation of FGF to its receptor FGFR, present on the underlying mesenchymal cells. ${ }^{4}$ CD44v3mediated activation of FGFR leads to limb outgrowth. CD44v6 isoforms collaborate with the receptor tyrosine kinases MET and VEGFR-2 that are crucial during development (reviewed in ref. 1). The extracellular part of CD44v6 binds HGF and VEGF(ref. 5) and is required for activation of the receptors while the cytoplasmic domain mediates signal transduction on binding to Ezrin-Radixin-Moesin proteins that provide a link to the actin cytoskeleton. ${ }^{6}$ In physiological conditions, MET-CD44 association is needed for synaptic transmission in the brainstem respiratory rhythm-generating network, ${ }^{7}$ whereas in patholological conditions, cooperation between CD44v6 and MET is essential for tumor growth and metastasis of pancreatic cancer cells. ${ }^{8}$ More recently, CD44, an established Wnt target gene, was also shown to act as a Wnt co-receptor at the level of LRP6 in a positive feedback loop. ${ }^{9}$

Hyaluronan $(\mathrm{HA})$ is the best characterized ligand of CD44 (ref. 10) and CD44/HA interactions control differentiation, proliferation, survival and migration of cells thereby playing a major role in tumor progression and metastasis. ${ }^{11}$ Binding of high molecular weight HA to CD44 augments CXCL12induced signaling and subsequent angiogenesis ${ }^{12}$ and $\mathrm{HA}$ binding to CD44 and subsequent interaction with neural Wiskott-Aldrich syndrome protein induces actin polymerization and EGFR activation. ${ }^{13}$

Despite the participation of CD44 in crucial signaling pathways, conventional Cd44 germ-line knockout mice $\left(\mathrm{Cd} 44^{-/-}\right)$develop normally and only display mild phenotypes in adulthood. ${ }^{14,15}$ The possibility that a substitute molecule takes over the co-receptor function of CD44 in the Cd44-/mice was therefore proposed. Several lines of evidence support this hypothesis. First, in clear contradiction with the

\footnotetext{
${ }^{1}$ Karlsruhe Institute of Technology, Institute of Toxicology and Genetics, Karlsruhe, Germany; ${ }^{2}$ University of Heidelberg, Institute of Physical Chemistry, Heidelberg, Germany; ${ }^{3}$ Karlsruhe Institute of Technology, DFG-Center for Functional Nanostructures, Karlsruhe, Germany; ${ }^{4}$ Heidelberg University Hospital, Institute of Pathology, Heidelberg, Germany; ${ }^{5}$ Laboratory for Immunological and Molecular Cancer Research, Third Medical Department with Hematology, Medical Oncology, Hemostaseology, Infectious Diseases, and Rheumatology, Oncologic Center, Paracelsus Medical University, Salzburg, Austria; ${ }^{6}$ Institut Clinique de la Souris IIlkirch, Illkirch, France; ${ }^{7}$ Spanish National Cancer Centre, Genes Development and Disease Group, Cancer Cell Biology Programme, Madrid, Spain and ${ }^{8}$ Institute for Integrated Cell-Material Sciences (WPI iCeMS), Kyoto University, Kyoto 606-8501, Japan

${ }^{*}$ Corresponding author: V Orian-Rousseau, Karlsruhe Institute of Technology, Institute of Toxicology and Genetics, Karlsruhe, Campus North, Postfach 3640, Karlsruhe 76021, Germany. Tel: +49 72160826523; Fax: +49 72160823354; E-mail: veronique.orian-rousseau@ @it.edu

${ }^{9}$ These authors contributed equally to this work.

Abbreviations: HA, hyaluronan; EGF, epidermal growth factor; EGFR, epidermal growth factor receptor; HGF, hepatocyte growth factor; VEGF, vascular endothelial growth factor; INL, inner nuclear layer; FGF, fibroblast growth factor; FGFR, fibroblast growth factor receptor; TPA, 12-0-tetradecanoylphorbol-13-acetate; AFM, atomic force microscopy; ICAM-1, intercellular adhesion molecule 1HABP, HA-binding proteinRICM, reflection interference contrast microscopy

Received 20.6.16; revised 18.9.16; accepted 23.9.16; Edited by D Aberdam
} 
a

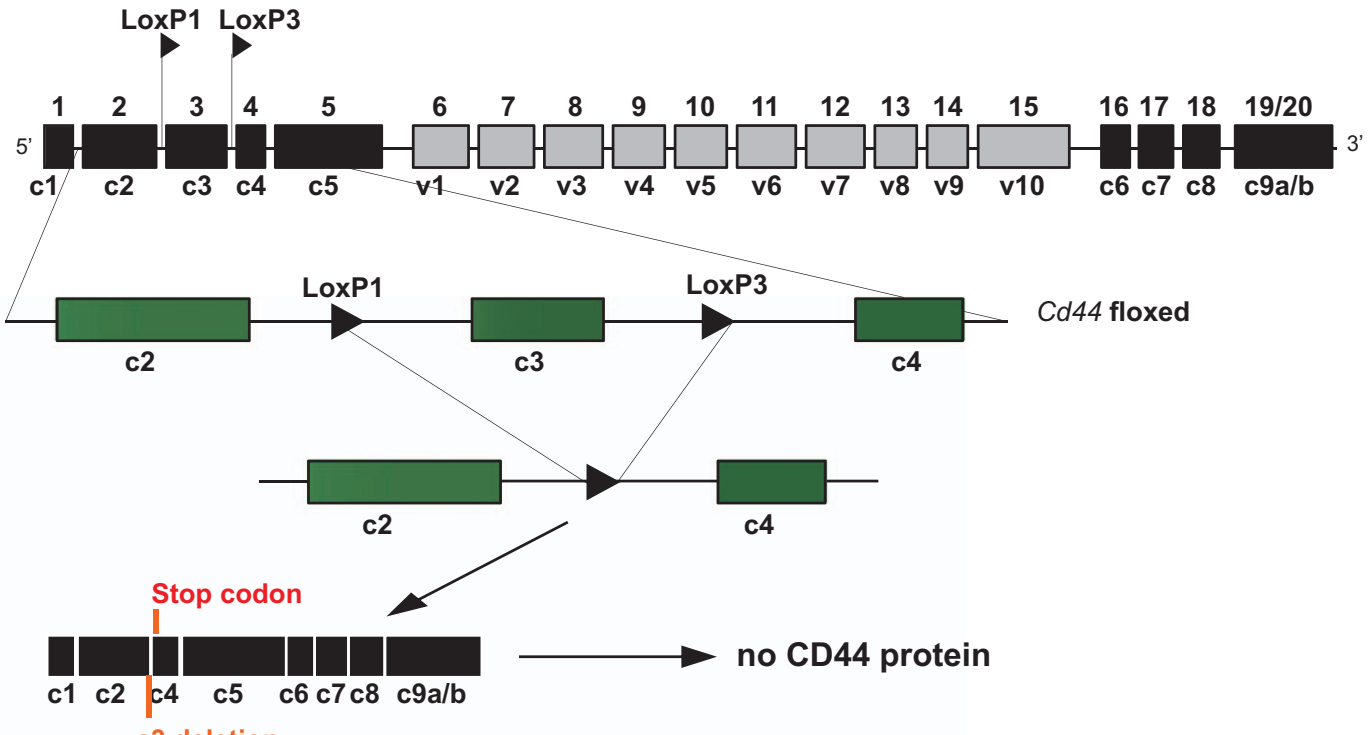

b
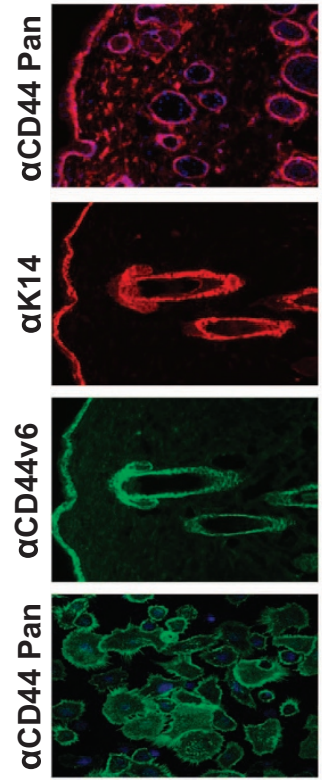

control
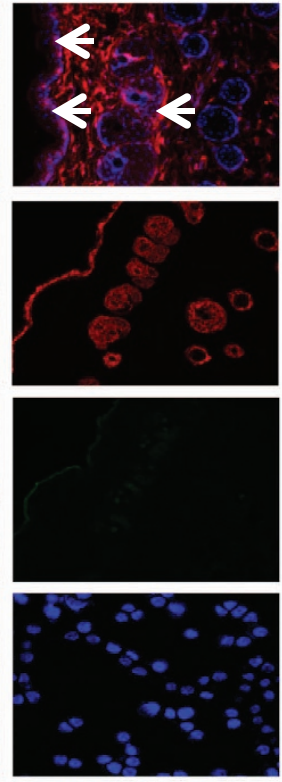

Co44 ${ }^{\text {ker }}$ d

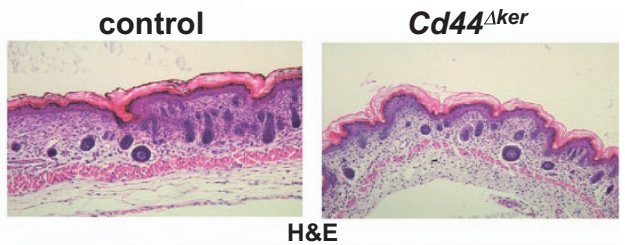

$H \& E$

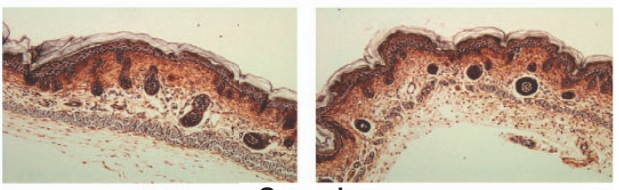

Gomori

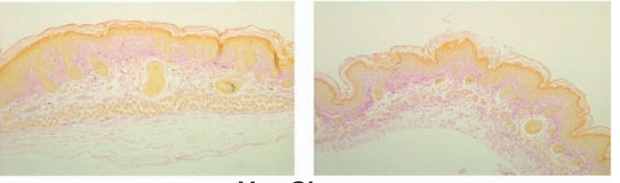

Van Gieson

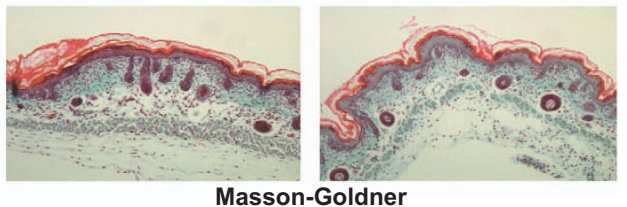

c

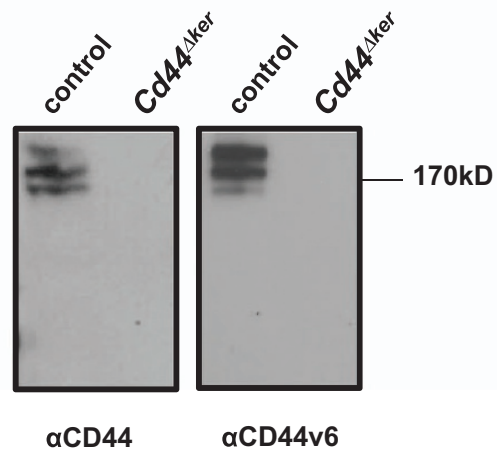


Figure 1 Knockout of CD44 in the skin. (a) Schematic representation of Cd44 conditional knockout allele. Upon crossing of the Cd44 floxed mice with K14Cre mice deletion of the Cd44 exon 3 leads to a frameshift and a stop codon disrupting the expression of all isoforms. (b) A pan CD44 antibody (IM7; red, green), a CD44v6 specific antibody (9A4; green) or a keratin 14 antibody (red) was used for indirect immune fluorescence staining of skin sections or keratinocytes (lower panel) harvested from Cd44 ${ }^{\Delta k e r}$ mice or control animals. Nuclei were counterstained with DAPI (blue). White arrows indicate areas where CD44 is removed (epidermis, hair follicles). (c) Western Blot analysis of lysates of keratinocytes, obtained from CD44 ${ }^{\mathrm{ker}} \mathrm{Cd} 44$ and control animals using a pan CD44 antibody (KM201) or a CD44v6 specific antibody ( $\left.\alpha 9 \mathrm{~A} 4\right)$. (d) New born Cd44 ${ }^{\mathrm{k} e r}$ or control skin stained for: H\&E, Gomori Trichrome, Verhoeff's Van Gieson and Masson Goldner

mild changes observed in the $C d 44^{-/-}$mice, transgenic animals expressing an antisense CD44 cDNA under the control of a keratin-5 promoter displayed a drastic skin phenotype. $^{16}$ Second, $\mathrm{Cd} 44^{-/-}, \mathrm{Met}^{+/-}$mice are haploinsufficient and most mutants die briefly after birth from a breathing defect that results from impaired synaptogenesis and axon myelination. ${ }^{7}$ This result suggests that CD44 and MET co-operate in vivo and that $\mathrm{Cd} 44^{-/-}$mice establish a rescue function to maintain activity of the MET pathway, which is not sufficient when MET levels are reduced. Such a rescue function is exemplified in hepatocytes where the intercellular cell adhesion molecule ICAM-1 takes over the co-receptor function of CD44 for MET when Cd44 is inactivated. ${ }^{17}$

For all these reasons, the best way to study CD44 functions in vivo is by cell-specific conditional inactivation. Therefore, we engineered a Cd44 floxed allele which when combined with Cre eliminates an essential constant exon (exon 3 designated c3, Figure 1a) and thereby all CD44 isoforms. Using this novel allele, we first investigated the role of CD44 in the skin. The skin is a protective barrier against influences of the external environment and the tightly controlled proliferation and differentiation of epidermal keratinocytes along the three epidermal layers is essential for homeostasis of this highly regenerative tissue. On wounding, a complex process involving inflammation, proliferation and remodeling ${ }^{18}$ takes place by which basal keratinocytes together with hair follicle stem cells are able to replace the epidermal cell population. ${ }^{19,20}$ Deregulation of these processes can lead to severe skin diseases such as hyperkeratosis, hyperplasia or cancer.

In this paper we show that while the skin of keratinocytedeficient Cd44 mice ( $C d 44^{\Delta k e r}$ ) appears normal, epidermal stiffness is decreased and in vivo wound healing delayed. Moreover, 12-O-tetradecanoylphorbol-13-acetate (TPA)induced cell proliferation and differentiation is also disturbed. These defects are cell autonomous and $C d 44^{\Delta k e r}$ keratinocytes display a decreased production of $\mathrm{HA}$, impaired adhesion, morphological dynamics and locomotion.

\section{Results}

Consequence of targeted Cd44 deletion in K14 expressing cells on skin homeostasis. A Cd44 floxed allele was generated by gene targeting in ES cells. Exon 3, present in all CD44 isoforms, was flanked by LoxP sites. Cre recombinase leads to excision of exon 3 , to the generation of an in-frame stop codon and subsequent disruption of protein synthesis in the cells where Cre is expressed leading to loss of all CD44 isoforms (Figure 1a). After germ-line transmission of the Cd44 floxed allele, Cd44 floxed mice were crossed with $K 14$ Cre mice ${ }^{21}$ to generate $C d 44^{\Delta k e r}$ animals. The K14Cre transgene is expressed as early as 9.5 days post-coitum in complex epithelia such as the epidermis. ${ }^{21}$ The removal of
Cd44 in the whole epidermis and in isolated primary keratinocytes of $C d 44^{\Delta k e r}$ mice was confirmed by histological stainigs (1b) PCR, Southern blot and Western blot analyses while qRT-PCR revealed a 70\% decrease in CD44 mRNA (Figures 1b, c and Supplementary Figure S1). The corresponding mRNA is not expressed as protein as shown in the western blot (Figure 1c). The western blot analysis also reveals that the majority of CD44 proteins expressed in the epidermis of control mice contain the v6 exon since the staining pattern with CD44v6 specific antibodies is nearly identical to that obtained with a pan CD44 antibody that recognizes all CD44 isoforms (Figure 1c). We confirmed that Cd44 was also inactivated in other K14-expressing organs such as the oral epithelium, tongue, mammary epithelium and thymus (data not shown).

To analyze potential morphological changes in the skin, $C d 44^{\Delta k e r}$ mice and control littermates were killed at different ages and the skin harvested for histological analysis (Figure 1d). A hematoxylin-eosin (H\&E) staining, a Gomori staining showing the distribution of the reticulin fibers, a Verhoeff's Van Gieson staining detecting collagen fibers and a Masson Goldner staining visualizing connective tissue were performed. As shown in Figure 1d (new born) but also in 2, 6 and 30 weeks old mice, (data not shown) no structural changes could be detected in the skin of $C d 44^{\Delta k e r}$ mice. Specifically, no edema was observed and the number or morphology of the dermal fibroblasts did not significantly differ. Moreover, fibers orientation seemed not to be affected and dermal stability was not disturbed. Finally, no epidermal hyperplasia or atypical keratinocytes were identified. Therefore, no gross abnormalities were observed in the dermis or the epidermis. Observation of $C d 44^{\Delta k e r}$ mice for a long time period (a year) did not reveal any spontaneous skin phenotype (data not shown).

Lack of CD44 in the skin interferes with wound healing. We next addressed the response of the skin to stress and performed wound healing experiments in $C d 44^{\Delta k e r}$ mice. To this end $4 \mathrm{~mm}$ full-thickness excisional wounds were performed on 10-12-week-old Cd44 ${ }^{\Delta k e r}$ mice and control littermates (Figure 2a) and the size of the wound determined. A difference in the relative wound area was observed between the two cohorts from day 1 on. The most drastic and statistically significant difference was observed at day 8 , where $C d 44^{\Delta k e r}$ mice showed a striking delay in wound closure while the wounds of Cd44-proficient mice were already completely closed (Figure 2a).

To analyze the contribution of keratinocytes in the reepithelialization (Figure 2b), wound sections were stained for keratin 6 (K6), which is specifically induced in hyperproliferative and migrating keratinocytes during wound healing. ${ }^{22-24}$ At each time point the distance between the 
migration fronts of the keratinocytes was larger in $C d 44^{\Delta k e r}$ mice, further demonstrating that inactivation of Cd44 in the epidermis leads to delayed wound healing (Figure $2 \mathrm{~b}$ ). In striking contrast, we did not observe any difference in wound closure between the $\mathrm{Cd44^{-/- }}$ germ-line knockout and control mice (Supplementary Figure S2A). This observation confirms that functions of CD44 are substituted in the germ-line knockout keratinocytes as was also the case in hepatocytes. ${ }^{17}$ This substitution apparently does not occur if the inactivation of the $\mathrm{Cd} 44$ gene arises at later times in embryogenesis, as is the case in the conditional knockout (the K14 promoter for Cre expression is active only from $\mathrm{E}$ 9,5) mice.

Impaired keratinocyte proliferation and differentiation in $\boldsymbol{C d} 44^{\boldsymbol{\Delta k e r}}$ mice. We next tested the response of epidermal Cd44 $4^{\text {ker }}$ keratinocytes to hair plucking and to TPA treatment ${ }^{25}$ (Figure 3).

As reported, ${ }^{26}$ hair plucking induced keratinocytes proliferation. Strikingly, quantification of Ki67 staining revealed that the proliferative response of $C d 44^{\Delta k e r}$ keratinocytes was much less pronounced than in controls (Figure 3a). Interestingly, however, hair regrowth did not appear delayed in $C d 44^{\Delta k e r}$ mice (not shown).

TPA treatment induced epidermal thickening of the skin as compared with acetone treatment as measured by $\mathrm{H} \& \mathrm{E}$ staining (Figure 3b). This increase was much less pronounced in $C d 44^{\Delta k e r}$ mice (Figure $3 b$ ). Taken together, these results indicate an impaired proliferative response of $C d 44^{\Delta k e r}$ keratinocytes. In support of this, isolated Cd44 ${ }^{\Delta k e r}$ keratinocytes showed reduced clonogenic efficiency as compared with controls and germ-line knockout keratinocytes (Figure 3c).

The epidermis consists of four different layers expressing various sets of keratins: The basal layer is characterized by expression of $\mathrm{K} 5$ and $\mathrm{K} 14$, the spinous layer by expression of $\mathrm{K} 1$ and $\mathrm{K} 10,{ }^{22,27}$ the granular layer produces filaggrin, ${ }^{28,29}$ and the cornified layer, loricrin. ${ }^{30,31}$ We made use of these markers to analyze the impact of CD44 on epidermal differentiation. Skin sections of TPA treated animals were stained immune fluorescently with the markers $\mathrm{K} 14, \mathrm{~K} 10$, filaggrin and loricrin (Figure $3 b$ ). Fluorescence intensity increased for all markers in TPA treated animals consistent with the induction of epidermal marker expression by TPA. When calculating the ratio of the stained layers relative to the total epidermal thickness, we observed that the relative thickness of each epidermal layer was not changed between acetone-treated controls and TPA-treated Cd44-proficient animals. However, in $C d 44^{\Delta k e r}$ mice, we observed a reduction in the relative thickness of the $\mathrm{K} 10$ and filaggrin-positive layers while the relative thickness of the $\mathrm{K} 14$ and loricrin layers appeared unaffected (Figure $3 \mathrm{~b}$ ). In addition, overall fluorescence intensity appeared weaker. These results indicate that genetic inactivation of $\mathrm{Cd} 44$ in the K14-expressing cells has also an impact on differentiation of keratinocytes. The lack of effect on relative $\mathrm{K} 14$ or loricrin levels might be due to the timing of the experimental endpoint.

Consistent with the in vivo data, we observed a delayed induction of keratin genes in vitro, when treating keratinocytes isolated from $C d 44^{\Delta k e r}$ mice for $2 \mathrm{~h}$ with TPA. This was most apparent for Keratin 5 and Keratin 14, and to a lesser extent for Keratin 1 (Supplementary Figure S2B upper part). Interestingly, TPA induction of several genes encoding for AP-1 family members that are robustly induced by TPA, was also delayed (Supplementary Figure S2B lower part).

Removal of Cd44 decreased the adhesion of keratinocytes to HA and their migration on HA surfaces. A prominent component of the extracellular matrix in the skin is $\mathrm{HA}^{32}$ As CD44 is the main receptor for $\mathrm{HA}^{10}$ we next performed a HA staining on isolated keratinocytes and on skin sections using the biotinylated HA-binding protein (Bio$\mathrm{HABP}$ ). Interestingly, the HABP staining did not reveal changes in the overall $\mathrm{HA}$ distribution in the skin sections neither during homeostasis nor during wound healing (Supplementary Figure S3A). This might be due to the contribution of cells from the dermis that still express Cd44. In contrast, in the isolated keratinocytes, a positive staining was detected only in $\mathrm{Cd}_{44^{+}}$keratinocyte cultures as shown in Figure $4 \mathrm{a}$. The decreased HA staining in Cd44 ${ }^{\Delta k e r}$ keratinocytes suggests that the cells are either unable to bind to HA and/or to produce $\mathrm{HA}$. We quantified the amount of $\mathrm{HA}$ produced by $\mathrm{Cd} 44^{+}$and $\mathrm{Cd} 44^{\Delta k e r}$ keratinocytes using solidphase ELISA in cell culture supernatants (Figure 4b). A significant decrease of HA production was observed in the supernatant of $C d 44^{\Delta k e r}$ cultures consistent with previous reports indicating that CD44 directly influences HA production. ${ }^{33,34}$

We next investigated the adhesion of cells on oligo-HA functionalized membranes (scheme in Supplementary Figure S3B) utilizing a combination of phase contrast and non-invasive live-cell imaging by reflection interference contrast microscopy (RICM). Figure $4 \mathrm{c}$ represents phase contrast and corresponding RICM images for $\mathrm{Cd} 44^{\Delta k e r}$ and $\mathrm{Cd} 44^{+}$ (control) keratinocytes. The area of tight cell adhesion can be identified from the dark area in RICM images without any additional fluorescent labeling (Figure 4c, highlighted by a red line). ${ }^{35}$ The fraction of adherent cells $(x)$ was significantly lower for $C d 44^{\Delta k e r}$ cells as compared with $\mathrm{Cd} 44^{+}$keratinocytes (Figure $4 d$, left). In addition to this defect in the collective cell adhesion, the adhesion area $A_{a d h}$ of individual keratinocytes was also significantly decreased by a factor of 3 on $C d 44$ inactivation (Figure 4d, right). These results indicate that the binding ability of $C d 44^{\Delta k e r}$ cells to HA is impaired.

We next investigated the morphological dynamics and migration of $C d 44^{\Delta k e r}$ and $C d 44^{+}$keratinocytes. The $C d 44^{\Delta k e r}$ keratinocytes that lack $\mathrm{HA}$ binding capability, show much longer and more persistent trajectories on oligo-HA functionalized membranes as compared with Cd44-proficient control keratinocytes (Figure $4 \mathrm{e}$, i-ii) similarly to control keratinocytes plated on pure membrane (no HA; Figure 4e, iii).

Dynamic morphological fluctuations of cells are active processes due to bending and stretching of their membranes and remodeling of their cytoskeleton by ATP consumption. ${ }^{36,37}$ The corresponding deformation energy can be estimated from the power spectrum analysis as reported previously. ${ }^{38}$ Figure $4 \mathrm{f}$ illustrates power spectra of $\mathrm{Cd} 44^{\mathrm{ker}}$ and $\mathrm{Cd} 44^{+}$keratinocytes on oligo-HA functionalized membranes and the corresponding data for $\mathrm{Cd} 44^{+}$cells on pure membranes (no HA; Supplementary Figure S3C). A 
a

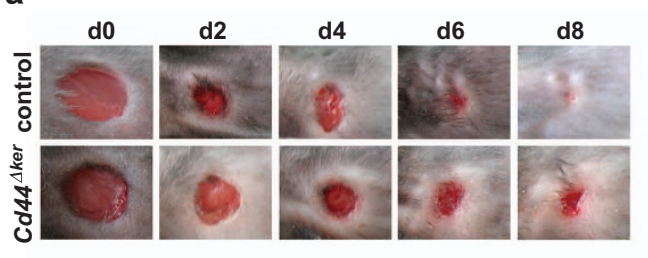

b

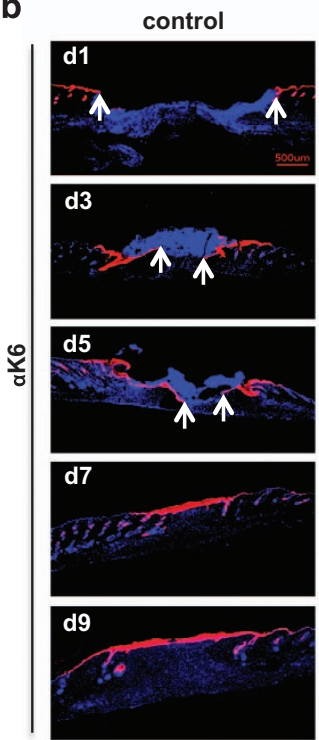

$C d 44^{\Delta k e r}$

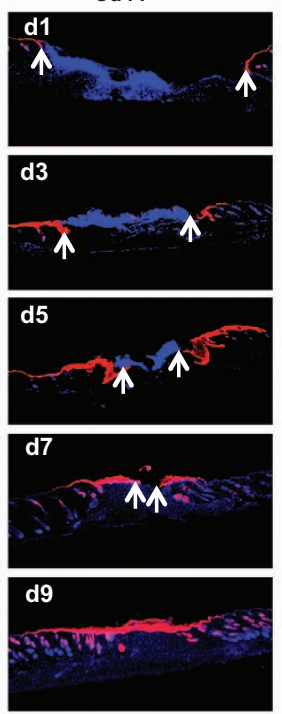

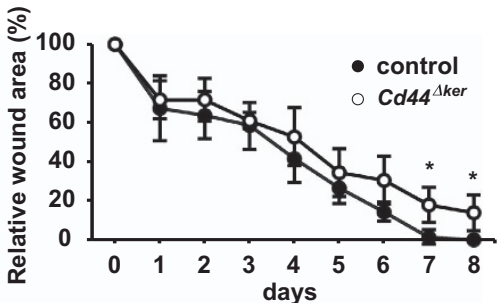

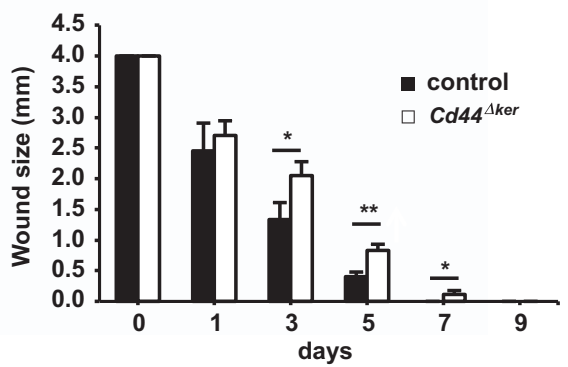

Figure 2 Impaired wound healing in Cd44 ${ }^{\Delta k e r}$ mice. (a) $4 \mathrm{~mm}$ full-thickness excisional dorsal skin wounds were performed on Cd44 ${ }^{\Delta k e r}$ and control animals and photographed at the indicated days. Wound closure was quantified by ImageJ and expressed relative to the initial wound area. (b) Wound sections were stained for keratin 6 (red) and nuclei counterstained with DAPI (blue). Images were taken by fluorescence microscopy (KEYENCY BZ-9000) using a $\times 2$ objective. Bar $=500 \mu \mathrm{m}$. Quantification of the distance between the keratinocyte migration fronts (white arrows). Bars represent means \pm S.E.M., $n=6$. Student's $t$ test: ${ }^{*} P<0.05,{ }^{* *} P<0.005$. Experiments were performed at least three times and gave similar results

maximum of the curve at mode $m=2$ suggested that keratinocytes predominantly undergo elliptic deformation as schematically depicted in the inset (Figure $4 \mathrm{f}$, left). The summation over all modes of deformation $\sum \hat{\Gamma}_{r, r}(m)$ reflecting the total energy consumption was strikingly decreased in Cd44 ${ }^{\Delta k e r}$ keratinocytes plated on HA functionalized membranes as compared with control keratinocytes while cells plated on pure membranes (no HA) did not show any deformations (Figure 4f, right).

Decreased epidermal stiffness in $C d 44^{\Delta k e r}$ mice. One essential role of the skin is to provide elasticity and resistance to stretch ${ }^{39}$ and the HA-related defects of keratinocytes lacking $\mathrm{Cd} 44$ could affect these intrinsic properties of the skin epidermis. We therefore examined the skin mechanical properties using atomic force microscopy (AFM) for nanoindentation, a method that quantifies tissue mechanical and elastic properties. ${ }^{40}$ AFM elasticity measurements were performed on mouse skin tissue slices and the indenter bead was positioned over the dermal or epidermal regions (Figure 4g, shown for new born mice, sections of 2-, 6- and 30 -week-old mice gave similar results) in the same experimental set-up.
AFM analysis revealed a striking decrease in epidermal stiffness in Cd44 ${ }^{\Delta k e r}$ mice, whereas the dermis was not affected. Reasons for the decrease in epidermal stiffness in $C d 44^{\Delta k e r}$ mice could be reduced HA production and/or lack of CD44-mediated adhesion to HA (Figure 4f). Since the mechanical environment of the wound site is important for the healing process, delayed skin wound healing in $C d 44^{\Delta k e r}$ mice could thus be the collective result of impaired keratinocyte proliferation, CD44/HA-mediated migration and adhesion together with altered biomechanical properties of the epidermis.

\section{Discussion}

CD44 is a multi-tasking family of proteins involved in signaling pathways essential for embryonic development. Therefore the mild phenotype of the Cd44 germ-line knockout mice ${ }^{14,15}$ suggested that CD44 is functionally substituted during embryogenesis. Such a lack of phenotype in germ-line knockout mice was described for several other genes and substitutions based on up-regulation of members of the same family or functionally related proteins have been identified. For instance fibroblast growth factor-2 (Fgf-2) knockout mice 
develop normally and display normal liver regeneration. ${ }^{41}$ VEGF was shown to substitute for FGF-2 and the VEGF inhibitor SU5416 inhibited liver regeneration in Fgf-2 knockout mice but not in control animals. ${ }^{42}$ Similarly, the inactivation of the tau gene encoding for a major neuronal microtubuleassociated protein essential for neuronal cell morphogenesis

a
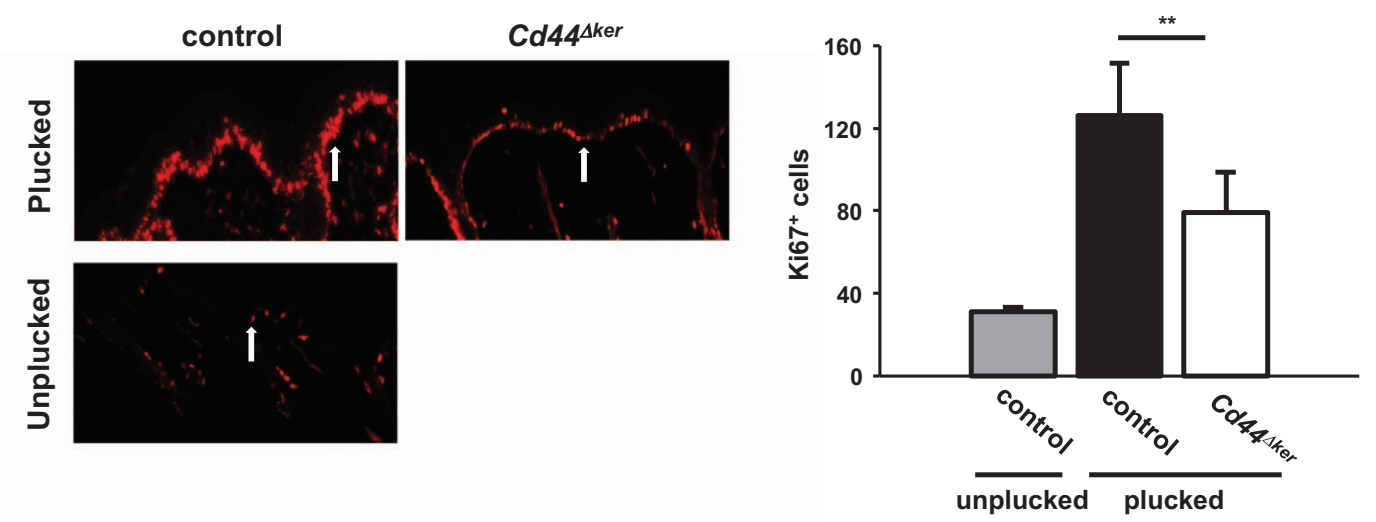

b

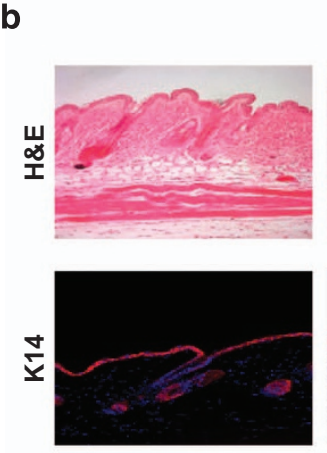

control

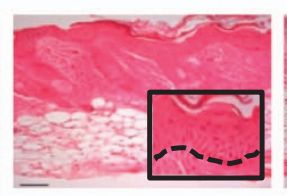

Cod44 4 ker
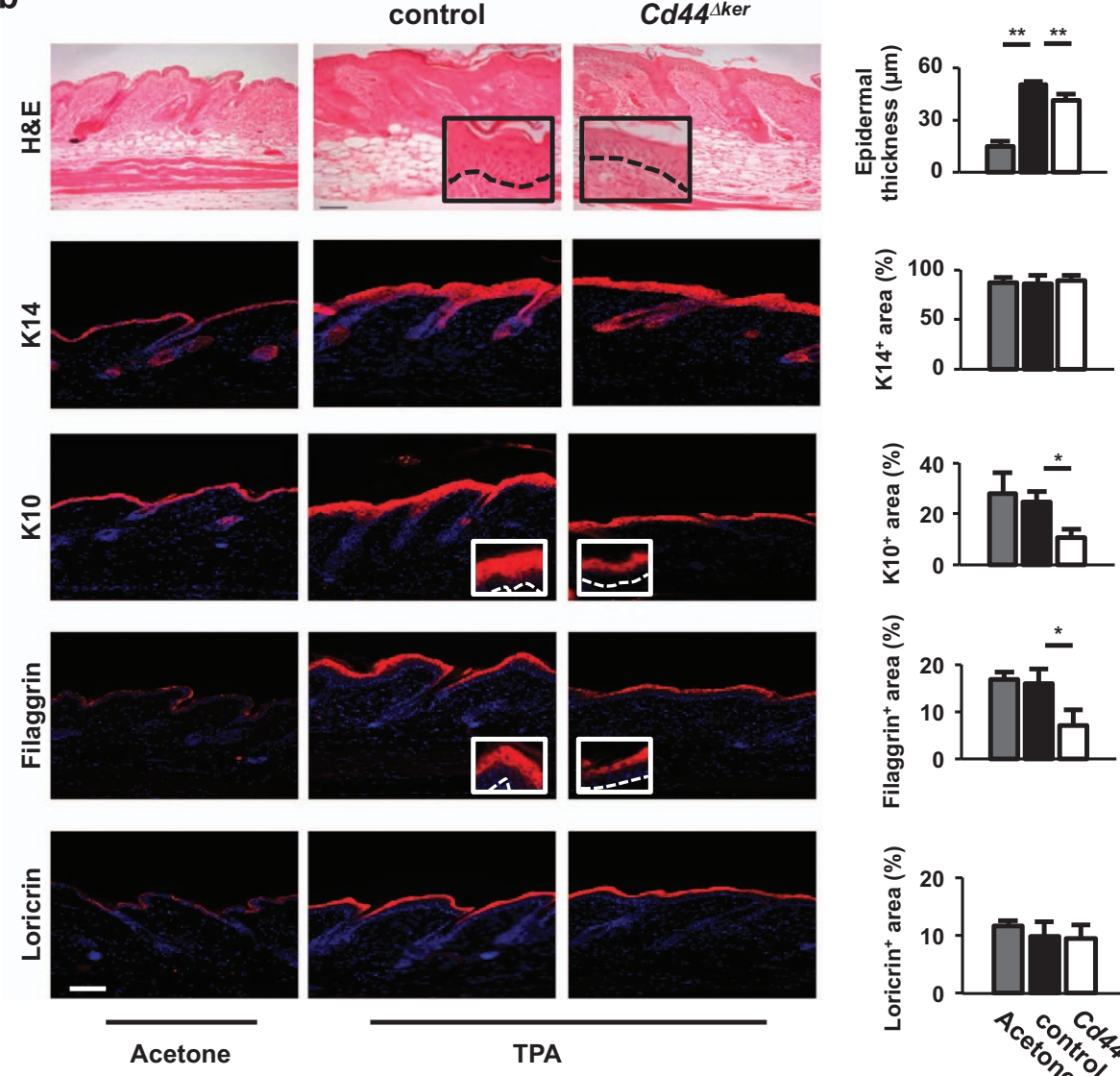

C

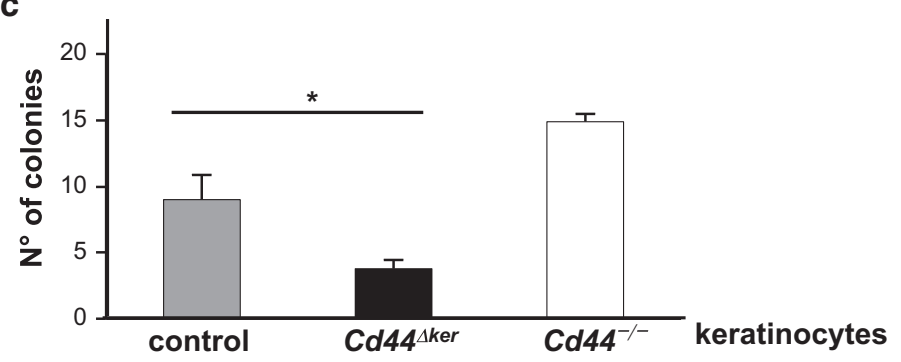


and axonal elongation and maintenance only led to mild defects in microtubule stability due to compensation by another protein, MAP-1A. ${ }^{43}$

In the case of CD44 several evidences support substitution events in the $\mathrm{Cd} 44^{-/-}$mouse. For example, the presentation of FGF produced in the apical ectodermal ridge to its receptor FGFR on the underlying mesenchymal cells by CD44v3 during limb development ${ }^{4}$ is overtaken by another heparan sulfate proteoglycan, upregulated in the $\mathrm{Cd} 44^{-/-}$mice. ${ }^{44}$ Furthermore, RHAMM, another HA receptor, compensates for CD44 in the $\mathrm{Cd}_{44^{-1}}$ mice. ${ }^{45}$ Finally, we have shown that ICAM-1 substitutes for CD44v6 in the $\mathrm{Cd} 44^{-/-}$mice as a coreceptor for MET in vivo and in vitro. ${ }^{17}$

The most appropriate strategy to identify functions of CD44 in vivo in various tissues and different stages of development is the use of a conditional inactivation of the Cd44 gene with the expectation that a substitute molecule will not be expressed. This strategy additionally allows deciphering cell autonomous functions of CD44 in the context of an otherwise wild-type tissue. Using the Cre-Lox technology to inactivate Cd44 we show in this paper that specific abrogation of CD44 in the skin epidermis has little apparent impact on the gross morphology of the skin. However, strikingly decreased epidermal stiffness as measured by AFM was detected on removal of Cd44. In addition, keratinocytes isolated from $C d 44^{\Delta k e r}$ mice show reduced $\mathrm{HA}$ production, impaired adhesion to $\mathrm{HA}$, reduced collective and individual migration, and morphological dynamics on HA functionalized surfaces. These results support a physiological function of CD44 in keratinocytes. Consistently, TPA leads to impaired epidermal thickening and differentiation in $C d 44^{\Delta k e r}$ mice. Delayed TPA response of $C d 44^{\Delta k e r}$ keratinocytes was also observed in vitro. Interestingly, we also saw a delayed TPA induction of members of the AP-1 transcription factor, an important regulator of epidermal differentiation. ${ }^{46-48}$ This suggests a possible modulation of AP-1 expression by Cd44. As Cd44 is itself a well-known target gene of $\mathrm{AP}-1^{\text {(ref. } 49)}$ a positive feedback regulation of AP-1 by CD44 might be in place in keratinocytes subjected to differentiation signals.

We also observed a proliferation delay in Cd44 ${ }^{\Delta k e r}$ epidermis subjected to hair plucking. In addition, in vivo wound healing was delayed in $\mathrm{Cd} 44^{\mathrm{ker}}$ animals. Interestingly, this delay was not observed in Cd44 germ-line knockout mice, further supporting a substitution of CD44 in early embryogenesis.

The most likely explanation for the delayed wound healing in $C d 44^{\Delta k e r}$ mice is an impairment of HA synthesis by keratinocytes and the inability of keratinocytes to attach and migrate on exogenous HA. The importance of HA synthesis for keratinocytes migration has been previously demonstrated by comparison of two different keratinocyte cell lines, carrying the HA synthase 2 (Has2) gene in sense or antisense orientation to increase or decrease HA synthesis, respectively. ${ }^{50}$ Keratinocytes expressing the Has2 sense gene migrated faster in an in vitro wounding assay, whereas Has2 antisense cells migrated more slowly. Interestingly, addition of exogenous HA to keratinocyte cultures did not restore the reduced migratory ability of Has2 antisense cells suggesting that the dynamic synthesis of $\mathrm{HA}$ controls keratinocyte migration, a key function during wound closure. ${ }^{50}$

The defects described above might result in a change in epidermal stiffness, which in turn affects wound healing. The AFM technology applied to a tissue layer allowed discriminating between the contribution of the dermis and epidermis, and suggests that the decreased epidermal stiffness might prevent rapid wound healing. Indeed, it has been previously demonstrated that stiff surfaces promote wound healing by stimulating epidermal cell proliferation and migration. ${ }^{51,52} \mathrm{Cd} 44^{\Delta k e r}$ keratinocytes lack CD44 as the main HA receptor and also produce reduced levels of $\mathrm{HA}$. The absence of CD44dependent HA binding might thus decrease the stiffness of the wound surface and thereby delay wound healing. Furthermore, the change in the dynamic fluctuation of $\mathrm{Cd} 44^{\Delta k e r}$ keratinocytes (Figure $4 \mathrm{f}$ ) might also contribute to the decreased stiffness of the epidermis.

In contrast to our observation, however, one report described delayed wound healing in $\mathrm{Cd}_{4} 4^{-/}$mice due to impaired vascularization. ${ }^{53}$ In another case, decreased HAmediated keratinocyte differentiation and lipid synthesis that interfered with normal epidermal permeability and barrier function was reported in $C d 44^{-/-}$mice. ${ }^{54,55}$ These contradictory results might be due to the different genetic backgrounds of the mice used in the different experimental settings as reported for genes such as Egfr. ${ }^{56}$

The gross morphology of the skin is not altered in $C d 44^{\Delta k e r}$ mice. This is in contradiction with drastic alterations in the structure of the dermis and epidermis of mice in which Cd44 was abolished in keratinocytes using an antisense CD44 construct expressed under the control of a $\mathrm{K} 5$ promoter. ${ }^{16}$ In addition, these Cd44 knockdown keratinocytes displayed a defect in $\mathrm{HA}$ uptake resulting in an accumulation of $\mathrm{HA}$ in the dermis. Some of the severe structural changes in the skin of these CD44 antisense mice could be attributed to off-target effects of antisense oligonucleotide expression in vivo. ${ }^{57}$ Interestingly, however, a change in skin elasticity, wound repair and keratinocyte proliferation were also observed in these antisense mice consistent with our observations in the Cd44 ${ }^{\Delta k e r}$ genetic model.

In conclusion, genetic inactivation of Cd44 in the keratinocytes allowed to more precisely defining the role of the CD44/ HA pair in epidermal repair during wound healing and in the

Figure 3 Loss of CD44 leads to impaired keratinocyte proliferation/differentiation. (a) Hair plucking was performed on the dorsal skin of Cd44 ${ }^{\Delta k e r}$ and control animals. Unplucked skin served as a control. The sections were stained for Ki67 (red) proliferation marker. Quantification is presented on the right side. (b) TPA-treated skin sections of $C d 44^{4 k e r}$ mice and control animals, and acetone-treated skin sections of control animals were analyzed by $\mathrm{H} \& \mathrm{E}$ (bar $\left.=50 \mu \mathrm{m}\right), \mathrm{K} 14, \mathrm{~K} 10$, filaggrin or loricrin stainings (bar $=75 \mu \mathrm{m}$ ). Epidermal/dermal junction is indicated by dashed lines. Quantification of epidermal thickness and of the stained area size, relative to epidermal thickness. (c) $C d 44^{\Delta k e r}$, control and germ-line KO keratinocytes were isolated and subjected to colony formation assay. Bars represent means \pm S.E.M., $n=5$. Student's $t$ test: ${ }^{*} P<0.05$, ${ }^{\star \star} P<0.005$. Experiments were performed at least three times and gave similar results 
regulation of keratinocyte differentiation, migration and proliferation. We genetically demonstrated important functions of CD44 in skin epidermis in homeostasis and acute stress conditions. Such genetic tools will allow dissecting CD44 functions in skin aging and in pathological situations such as skin hyperplasia and cancer. a

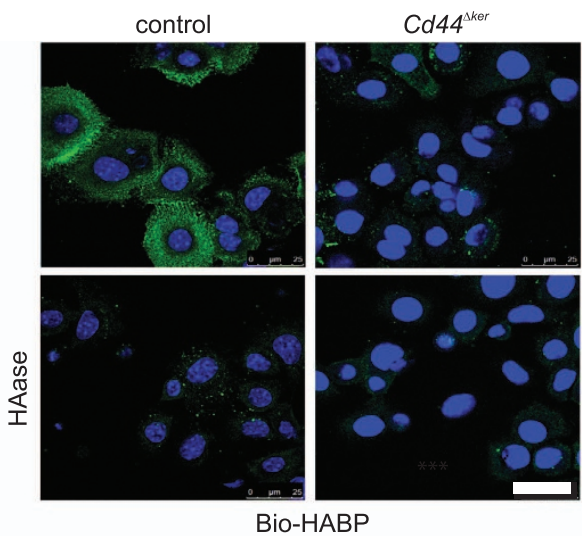

C
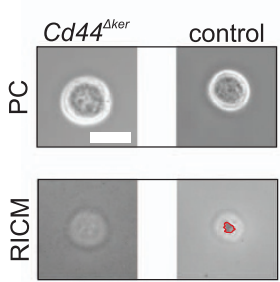

d

i

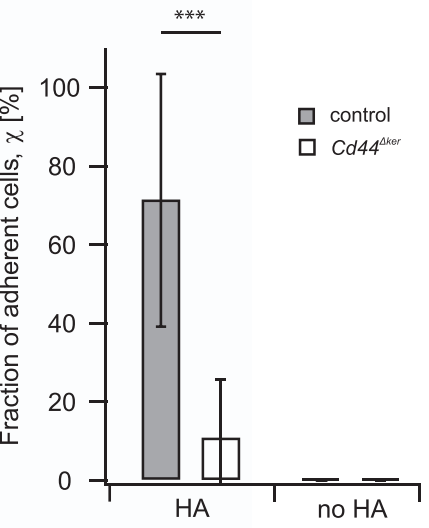

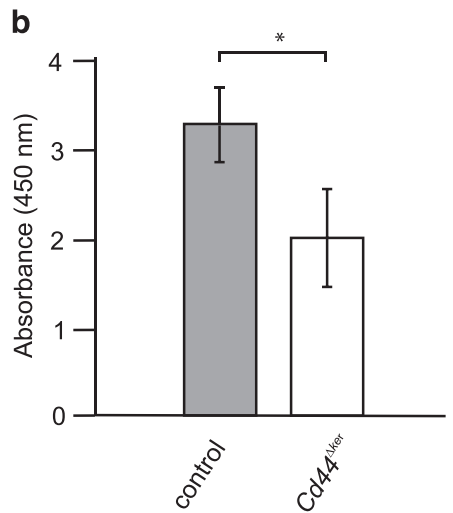

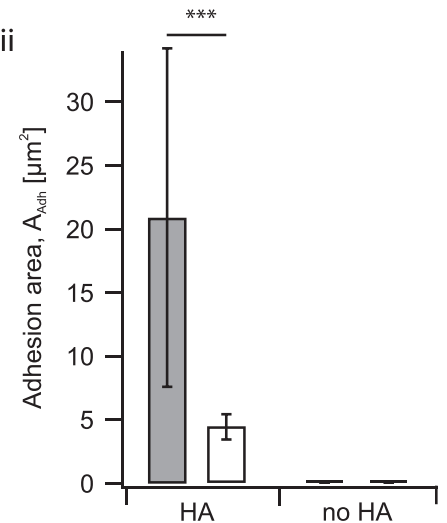

e

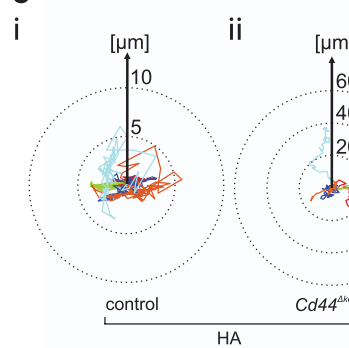

iii

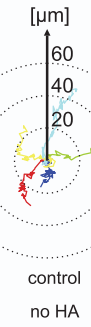

f
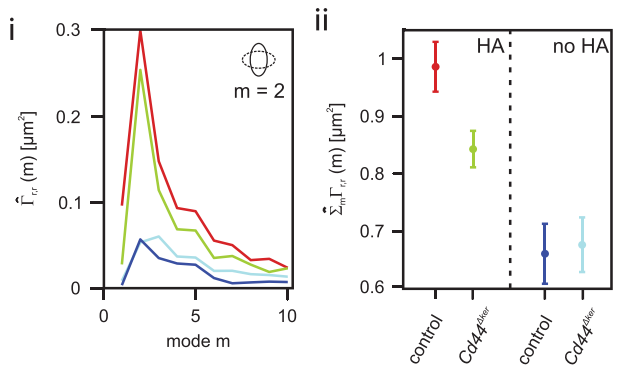

g
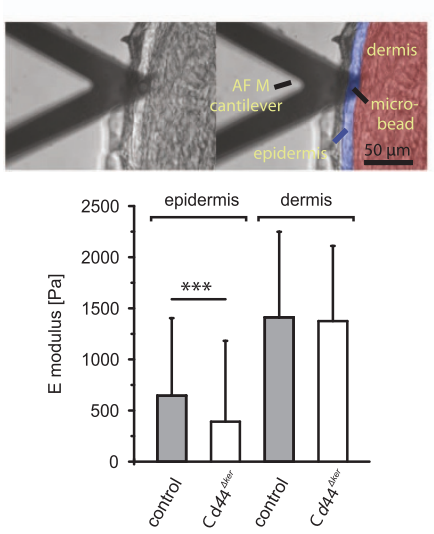


\section{Materials and Methods}

Generation of $\mathbf{C d} 44$ floxed mice, other mouse strains. pCD44-KO vector consisting of genomic Cd44 exons 2 and $3(10,7 \mathrm{~kb})$ derived from the mouse strain 129/01a and a single Lox-P site inserted downstream from exon 3 were obtained from Therese Touchy (Beaverton, OR, USA). The short arm of Cd44 (3623 bp) was cut out from pCD44-KO vector with PspOMl and Nhel, and was ligated in pTVFlox-0 5' (constructed by Dieter Riethmacher and Karin Gottschling) from the neo-cassette with Notl and Xbal to obtain the pTVFlox-s.a. vector. The long arm of Cd44 (6624 bp) was cut out from the pCD44-KO vector with Hpal and BamHI, and inserted into pTVFlox-s.a. vector with Hpal and Bgll 3' from the neocassette. The final construct abbreviated as PCD44-cKO was linearized by Bsal and electroporated into 129S2 ES cells. Correctly targeted ES cells were identified, the neo-cassette removed using pCMV-Cre and positive clones injected into C57BL/6 blastocysts and transferred to $3 \mathrm{H} 1$ foster mothers. After germ-line transmission, Cd44 floxed mice (Cd4t fl/ft) were crossed to K14Cre mice (Daniel Metzger, Strasbourg, France) to result in $C d 44^{\Delta k e r}$ mice. All experiments were performed with $\mathrm{Cd} 44^{\Delta k e r}$ mice backcrossed to C57BL/6 mice for eight generations. Controls and mutants were identified by PCR genotyping on tail DNA using the following primers: Cd44- forward 5'-GGG AGC ATT GGC TGA CAA CA-3', Cd44- reverse 5'-TTA CTC TGATCA TGG CTC TC-3', K14cre forward 5'-ATT TGC CTG CAT TAC CGG TC-3', K14cre reverse 5'-ATC AAC GTT TTG TTT TCG GA-3'.

Cd44 germ-line knockout mice $\left(\mathrm{Cd}_{4} 4^{-1-}\right)$ with a C57B//6 background were a kind gift from Tak Mak (Toronto, Ontario, Canada). C57BI/6J wild-type mice were obtained from Charles River Laboratory (Sulzfeld, Germany). Animals were housed and maintained under specific pathogen-free conditions in facilities approved by the Regierungspräsidium Karlsruhe. All animals were handled according to German regulations for animal experimentation. Experiments were authorized by the Regierungspräsidium (35-9185.81/G-110/10).

Antibodies and reagents. The mouse CD44 pan antibody IM7 (BD Biosciences, Heidelberg, Germany, \#553131) and the mouse CD44v6 antibody 9A4 have been described. ${ }^{58}$ The antibodies directed against Filaggrin (\#PRB-417P), Keratin 6 (\#PRB-169-P), Keratin 10 (\#PRB-159P), Keratin 14 (\#PRB.155P) and Loricrin (\#PRB-145P) were purchased from Covance, HiSS Diagnostics (Freiburg, Germany). Isotype control antibodies mouse IgG (\#Sc-2025) or rat IgG (\#sc-2026) were from Santa Cruz (Heidelberg, Germany), the secondary antibodies: goat antirabbit Alexa Fluor 488 (\#A-11034), goat anti-rabbit Alexa Fluor 546 (\#A-11071), goat anti-rat Alexa Fluor 488 (\#A-11006) and goat anti-rat Alexa Fluor 546 (\#A-11081) were purchased from Invitrogen (Karlsruhe, Germany). Secondary antibodies linked to horseradish peroxidase were from Dako (Hamburg, Germany, \#P045001). The antibody against Ki67 was obtained from Abcam, Cambridge, UK (\#Ab15580). 1-stearoyl-2-oleoyl-sn-glycero-3-phosphocholine (SOPC) and 1,2-dioleoyl-sn-glycero-phosphoethanolamine-3-N-(cap biotinyl; biotin-DOPE) were purchased from Avanti Polar Lipids (Alabaster, AL, USA), and neutravidin from Life Technologies (Darmstadt, Germany). Hydrazide-PEG 4 -Biotin and 1-ethyl-3(3-diMEThylaminopropyl)carbodiimid were purchased from Thermo Fisher Scientific (Waltham, Massachusetts, USA).
Primary keratinocyte culture. All experiments were exclusively performed with keratinocytes isolated from mouse tail skin epidermis. Mice were sacrificed by decapitation and the tail was removed, vertically cut with a razor and the skin was pulled off. The epidermis was separated from the dermis by placing the skin (dermal side down) into $1 \%$ trypsin for $1 \mathrm{~h}$ at $37^{\circ} \mathrm{C}$. The epidermis was cut into small pieces, transferred into Defined Keratinocyte-SFM (Serum Free Medium) (Life Technologies) containing $10 \%$ FCS and $0.25 \mathrm{mg} / \mathrm{ml}$ DNase 1 and incubated $1 \mathrm{~h}$ at $37^{\circ} \mathrm{C}$. Disaggregated cells and tissue clumps were poured through a sterile cell strainer $(70 \mu \mathrm{m})$, centrifuged and re-suspended in Defined Keratinocyte-SFM medium, seeded on coated plates (Coating Matrix Kit, Life technologies) and incubated at $37^{\circ} \mathrm{C}, 5 \% \mathrm{CO}_{2}$. On the next day the cells were washed with PBS and suspended in new Keratinocyte-SFM medium. Cells were used after 2 -5 days of culture.

Preparation of genomic DNA from different tissues and from keratinocytes. Genomic DNA from skin, liver, kidney and lung were isolated as described. ${ }^{59}$ Keratinocytes were lysed in a buffer containing $50 \mathrm{mM}$ Tris- $\mathrm{HCl}, \mathrm{pH}$ 7.6, $1 \mathrm{mM} \mathrm{EDTA}, 100 \mathrm{mM} \mathrm{NaCl}, 0.2 \%$ SDS and proteinase $\mathrm{K}(100 \mu \mathrm{g} / \mathrm{ml})$ for $2 \mathrm{~h}$ at $60{ }^{\circ} \mathrm{C}$. DNA was precipitated by addition of $100 \%$ ethanol followed by centrifugation for 2 min at 10000 r.p.m. Pellets were washed with $70 \%$ ethanol, centrifuged for $2 \mathrm{~min}$ at 10000 r.p.m., dried and suspended in TE buffer.

Southern blot analysis. Genomic DNA $(15 \mu \mathrm{g})$ from mouse keratinocytes was digested with Hind III (Fermentas, St. Leon-Rot, Germany) and resolved on a $0.8 \%$ agarose gel. $0.4 \mathrm{M} \mathrm{NaOH}$ was used to transfer DNA fragments from the gel to a Zeta Probe GT Membrane (Bio-rad, Munich, Germany). The membrane was baked for $2 \mathrm{~h}$ at $80^{\circ} \mathrm{C}$. Hybridization was performed at $65^{\circ} \mathrm{C}$ overnight using the Church buffer. A probe was produced via PCR from the Bacterial artificial chromosome RP23-408N14 (BACPAC Resources-CHORI, Oakland, CA, USA) using the primers $\mathrm{Cd} 44^{\mathrm{SB}}$ forward 5'-AAG CAC TTC ACT GGC TGA GC-3', Cd $44^{\text {SB }}$ reverse $5^{\prime}$-TCT GCA CAG TCA AGA CTC TGC-3'.

RNA isolation and RT-PCR. Total RNA was isolated using Trizol (SigmaAldrich, Taufkirchen, Germany), complementary DNA was synthesized using Ready-To-Go-You-Prime-First-Strand Beads (GE Healthcare (VWR), Bruchsal, Germany) and RT-qPCR performed using GoTaq RT-qPCR Master Mix (Promega, Mannheim, Germany) and Eppendorf fluorescence thermocyclers (Eppendorf, Wesseling-Berzdorf, Germany), all following manufacturers' instructions. The $2^{\Delta \Delta C T}$ method was used to quantify amplified fragments. Expression levels were normalized using at least one housekeeping gene (rps29 and/or rp/4). The sequence of the GPCR primers can be found in ref. 47. The sequences of the primers used for CD44 are: 5'-GCACTGTGACTCATGGATCC-3' present in exon 16 and 5'-GCACTGTGACTCATGGATCC-3' in exons 17-18.

Wound healing experiments. Ten to twelve-week-old male $C d 44^{\Delta k e r}$ mice and control animals were anesthetized by intraperitoneal injection of ketamine ( $80 \mathrm{mg} / \mathrm{kg}$ body weight)/xylazine (10 mg/kg body weight). The dorsal hair was shaved and the exposed skin was cleaned with $70 \%$ ethanol. Full-thickness excisional skin wounds (usually two wounds) were performed on both sides of the dorsal middle line using a $4 \mathrm{~mm}$ biopsy-punch. The clot was removed daily and

Figure $4 \mathrm{HA}$ production and binding in $C D 44^{\Delta k e r}$ keratinocytes. (a) HA staining (green) of mouse keratinocytes derived from Cd44 ${ }^{\Delta k e r}$ mice or control animals was performed using a Bio-HABP detected with streptavidin-Alexa 488. Nuclei were counterstained with DAPI (blue). Images were taken with a SpE confocal microscope. Bar $=25 \mu \mathrm{m}$. Control cells were also pretreated with hyaluronidase (HAase) before staining. (b) HA production by keratinocytes from $\mathrm{Cd} 44^{4 k e r}$ mice or control animals on incubation for $24 \mathrm{~h}$ in culture dishes. Bars \pm S.E.M. $n=3$. Student's $t$ test: ${ }^{*} P<0.05$. (c) Phase contrast and RICM images of $C d 44^{\Delta k e r}$ and $C d 44^{+}$keratinocytes on supported membranes displaying oligoHA (scheme in Supplementary Figure S3A) at an average intermolecular distance $\left.\left(<d_{\text {oligo-HA }}\right\rangle\right)$ of $\sim 6 \mathrm{~nm}$ at $5 \mathrm{~h}$ after cell seeding. Dark spots (red encircled) in RICM images correspond to areas of tight cell adhesion. (d) Determination of the fraction of adherent $C d 44^{\Delta k e r}$ and $C d 44^{+}$keratinocytes $(\chi)$ or their adhesion area $\left(A_{a d h}\right)$ on functionalized (HA) or non-functionalized (no HA) membranes. All data are mean \pm S.D. of $n=30$ cells of three independent experiments. ${ }^{*} P<0.05$; ${ }^{* *} P<0.01 ;{ }^{* * *} P<0.001$ (Mann-Whitney test). (e) Five exemplary tracks of individual keratinocytes in polar plots obtained from cell tracking of 20 keratinocytes per condition by time-lapse movies. (f) Power spectrum of $\mathrm{Cd} 44^{\Delta \mathrm{ker}}$ and $\mathrm{Cd} 44^{+}$keratinocytes on oligo-HA functionalized membranes or control membranes obtained by a Fourier transformation $\mathrm{Ft}(r(\theta, t))$ of the corresponding amplitude maps (Supplementary Figure S3C). This analysis yields the predominant mode $m$ of cellular deformation by which keratinocytes dissipated energy. The integration over all modes of deformation, $m$, results in the determination of the total power of deformation $\sum \hat{\Gamma}_{r, r}(\theta, t)$. All data are mean \pm S.E.M. of $n=20$ cells of three independent experiments. (g) AFM measurement of full-thickness skin biopsies from new born Cd44 ${ }^{4 k e r}$ and control mice (pictures). Young's $\mathrm{E}$ modulus of mouse epidermal and dermal tissues. AFM measurement of full-thickness skin biopsies from new born Cd44 $\Delta$ ker and control mice (pictures). Young's E modulus of mouse epidermal and dermal tissues presented as boxwhisker-plots. At least 15 different locations per skin region were tested, using skin slices from at least three different animals. The statistical significance between experimental groups was determined using a one-way ANOVA test: NS $={ }^{* \star *} P<0.001$ 
pictures of the wound area were taken. The wound area was calculated using the Image J Program (National Institutes of Health, Bethesda, MD, USA). The wound closure was expressed as percentage of recovery with respect to the initial wound area.

To specifically measure the contribution of keratinocytes, the wound healing experiment was performed without removing the clot. Animals were killed at indicated time points and the wounded tissue including the surrounding wound margin skin was harvested and embedded in Tissue Freezing Medium (Leica Microsystems, Wetzlar, Germany). Wound sections were stained immune fluorescently for the activation marker keratin 6 and the distance between the migration fronts of the keratinocytes was determined.

For each experiment six wounds per genotype were analyzed. Error bars represent the S.E.M. statistical analysis was performed by Student's $t$ test. $P<0.05$ or $P<0.005$ is indicated by one and two asterisks respectively.

TPA treatment. Seven-week-old female animals were shaved on the dorsal area of the skin and $48 \mathrm{~h}$ later TPA ( $5 \mathrm{nM} / 100 \mu \mathrm{l}$ acetone) or acetone alone was locally applied topically on the back skin. This treatment was performed two times every 48 h. 48 h after the last treatment, the skin was harvested and fixed in $4 \%$ paraformaldehyde overnight, processed in a tissue processor for dehydration and embedded in paraffin for histological analyses. Sections were stained using H\&E or with different sets of keratin markers.

Hair plucking. The hair was plucked on a $0.5 \mathrm{~cm}^{2}$ dorsal surface of 8 -week-old female mice. 10 days later hair from the same area was plucked again and the treated region was harvested after 2 more days. Thereafter, the tissues were stained immune fluorescently for the proliferation marker Ki67. For quantification Ki67-positive cells were counted. As a control, skin samples were taken at a distance from the plucked surface.

Colony formation assay. Murine keratinocytes of each genotype were seeded on coated (Coating Matrix mix, Thermo Fisher Scientific, Cat.nr. R-011-K) 6 -well plates at 1000 cells/well. The cells were grown for 10 days. Plates were gently washed once with PBS and fixed with $3.7 \%$ formalin for 10 min at RT. After fixation, plates were rinsed once again with PBS and colonies stained with $0,2 \%$ crystal violet solution in $10 \%$ ethanol for $15 \mathrm{~min}$ at RT. To remove the excess staining, the plates were rinsed several times with PBS. Colonies of more than 50 cells were counted under the microscope.

Immunofluorescence and immunohistochemistry. For immunofluorescence analysis, frozen or paraffin sections of the skin were cut into $7 \mu \mathrm{m}$-thick sections and mounted on glass slides. The unspecific binding of the antibody was blocked by $5 \%$ FCS in PBS for $1 \mathrm{~h}$ at room temperature followed by overnight incubation with primary antibodies diluted in blocking solution: IM7 (2 $\mu \mathrm{g} / \mathrm{ml}) ; 9 \mathrm{~A} 4$ $(2 \mu \mathrm{g} / \mathrm{ml}) ; \alpha$ filaggrin $(1 \mu \mathrm{g} / \mathrm{ml}) ; \alpha$ keratin $6(1 \mu \mathrm{g} / \mathrm{ml}) ; \alpha$ keratin $10(1 \mu \mathrm{g} / \mathrm{ml}) ; \alpha$ keratin $14(1 \mu \mathrm{g} / \mathrm{ml}) ; \alpha$ loricrin $(1 \mu \mathrm{g} / \mathrm{ml})$. After 3 washes with PBS, the respective Alexa Fluor labeled secondary antibodies (1:500) were applied with DAPI (Sigma-Aldrich) in blocking solution for $1 \mathrm{~h}$ at room temperature, washed thee times with PBS and mounted.

Keratinocytes were fixed in $4 \%$ paraformaldehyde for 20 min at room temperature. After washing for three times with PBS cells were incubated with $5 \%$ FCS in PBS for $1 \mathrm{~h}$ at room temperature treated with IM7 $(2,5 \mu \mathrm{g} / \mathrm{ml})$ over night, rinsed in PBS for 3 times, incubated with Alexa Flour labeled secondary antibody $(1: 500)$ for $1 \mathrm{~h}$ at room temperature, washed and then mounted using the Fluorescent Mounting Medium (Dako).

For H\&E staining, paraffin sections were deparaffinized in xylene, rehydrated (100\% EtOH 1 min, 95\% EtOH 1 min, 80\% EtOH 1 min, 70\% EtOH 1 min, $\mathrm{H}_{2} \mathrm{O}$ ), stained with hematoxylin for 1-5 min, rinsed in $\mathrm{H}_{2} \mathrm{O}$ and stained with eosin for 1 min. Thereafter, slides were dehydrated $(95 \% \mathrm{EtOH} 1 \mathrm{~min}, 100 \% \mathrm{EtOH} 1 \mathrm{~min}$, Xylene $5 \min 2 X)$ and mounted.

To detect HA by means of a biotinylated HA-binding proteins (Bio-HABPs, $2.5 \mu \mathrm{g} / \mathrm{ml}$, Merck, Darmstadt, Germany) cells were seeded in 12-well plates on sterile cover slips and starved for $24 \mathrm{~h}$. Cells were fixed for 10 min with $4 \%$ paraformaldehyde (PFA) in PBS, then blocked with 5\% FCS in PBS and afterwards incubated overnight with the biotinylated HA-binding protein. After incubation with Streptavidin/Alexa488 $(0.4 \mu \mathrm{g} / \mathrm{ml}$ Invitrogen) for $45 \mathrm{~min}$, nuclei were stained with DAPI (Dako, Hamburg, Germany). For controls, cells were incubated with $50 \mathrm{U} / \mathrm{ml}$ Bovine Testis hyaluronidase (Sigma-Aldrich) before fixation.
Functionalization of supported membranes with biotinylated HA oligomers

Preparation of biotinylated hyaluronic acid oligomers: HA oligomers (13-16 monomers, $0.334 \mathrm{mg} / \mathrm{ml})$ in $0.1 \mathrm{M}$ MES buffer at pH $4.5(1.00 \mathrm{mg}, 91 \mathrm{nmol})$ were incubated with a 10-fold molar excess of hydrazide- $\mathrm{PEG}_{4}$-Biotin $(0.50 \mathrm{mg}, 910 \mathrm{nmol})$ and 1-ethyl-3-(3-diMEThylaminopropyl)carbodiimid $(0.17 \mathrm{mg}$, $n=912 \mathrm{nmol}$ ) at $\mathrm{pH} 4.5$ (addition of $1 \mathrm{mM} \mathrm{HCl}$ ). The reaction mixture was stirred for $12 \mathrm{~h}$ in an end-to-end motion at $25^{\circ} \mathrm{C}$, transferred to a pre-wetted Slide-A-Lyzer dialysis cassette with a molecular weight cut-off of $2 \mathrm{kDa}$ (Thermo Fisher Scientific, Waltham, MA, USA) and dialyzed exhaustingly against HBS buffer (10 mM Hepes, $150 \mathrm{mM} \mathrm{NaCl}, \mathrm{pH}$ 7.5).

Preparation of HA functionalized supported membranes: Cell incubation chambers were prepared according to our previous protocol. ${ }^{38}$ Then, supported membranes consisting of $2 \mathrm{~mol} \%$ biotin-DOPE in SOPC were deposited inside the cell incubation chambers by vesicle fusion. ${ }^{60}$ Subsequent functionalization of the supported membrane with neutravidin $(10 \mathrm{nM})$ and oligo-HA $(10 \mathrm{nM})$ were performed as described. ${ }^{38}$ As the anchor lipids biotin-DOPE are monomerly incorporated into the matrix lipids, the average lateral distance between lipid anchors $\langle d\rangle$ and thus oligomers can be estimated from the molar fraction $x$ of lipid anchors by inserting the value of the lipid area of $A_{\text {lipid }}=65 \AA^{2}$.

$<d>=\sqrt{\frac{A_{\text {lipid }}}{x}}$.

Excess HA oligomers were removed by rinsing with Keratinocyte-SFM medium. The measurement chambers were equilibrated at $37^{\circ} \mathrm{C}$ before use for cell adhesion and migration experiments.

Reflection interference contrast microscopy. Keratinocytes $\left(5 \times 10^{4}\right.$ cells $/ \mathrm{cm}^{2}$ ) were incubated for $5 \mathrm{~h}$ at $37^{\circ} \mathrm{C}$ and $5 \% \mathrm{CO}_{2}$ in cell incubation chambers in Keratinocyte-SFM medium. RICM was undertaken as described. ${ }^{38}$ Image corrections for shot noise and parabolic illumination profile were performed as described. ${ }^{61}$ The measured intensity was converted into heights, applying the RICM theory for finite INA and multiple reflecting layers, with refractive indices $n=1.525$ (glass substrate), $n=1.486$ (lipid membrane), $n=1.335$ (cell medium) and $n=1.37$ (cytosol). ${ }^{62}$ The adhesion area $A_{\text {Adh }}$ was calculated from the average height and $\mathrm{s}$. d. in each pixel. The fraction of adherent cells $\chi$ was determined by dividing the number of adherent cells, which were identified by RICM by pixel thresholding, by the total number of cells visible on phase contrast images.

Statistical image analysis of stochastic morphological dynamics. Keratinocyte migration was followed in cell incubation chambers $\left(5 \times 10^{4} \mathrm{cell} / \mathrm{s} / \mathrm{cm}^{2}\right)$ in Keratinocyte-SFM medium by recording time-lapse movies over $12 \mathrm{~h}$ with a frame rate of $0.017 \mathrm{~Hz}$ with a Keyence BZ-9000 microscope (Keyence, Osaka, Japan), which was equipped with a Plan Fluor 40x/0.6 air objective. The movies were drift-corrected utilizing cross-correlation analysis. Morphological dynamics of migrating keratinocytes were quantified as described previously. ${ }^{38}$ The peripheral edge of each cell $r$ in each phase contrast image of a time-lapse series of 60 min was detected by pixel contrast and plotted as a function of $\Theta$ for $0-360^{\circ}$ in laboratory coordinates. An amplitude map $r(\theta, t)$ was obtained by displaying the time evolution of the radial distances $r$. Thereafter, the corresponding autocorrelation map $\Gamma_{r r}(\theta, t)$ was calculated according to

$\Gamma_{r r}(\theta, t)=\frac{\langle r(\theta+\Delta \theta, t+\Delta t) \cdot r(\theta, t)\rangle}{\left\langle[r(\theta, t)]^{2}\right\rangle}$

A Fourier transform of the radial distance in $\Theta$ and tresulted in the determination of different modes $m$ of deformation.

$\hat{\Gamma}_{r, r}(\theta, t)=\langle F T(r(\theta, t)) * F T(r(\theta, t))\rangle$

Finally, an integration over all modes $m$ of deformation was performed to quantify the total power of cell deformation $\sum \hat{\Gamma}_{r, r}(m)$.

Statistics. The underlying number of experiments per data point corresponds to three experiments. In summary, the fraction of adhered cells and the adhesion area $A_{\text {Adh }}$ were calculated for a total number of 30 cells per data point, which were presented in the corresponding figures as means \pm s.d. Data characterizing the morphological dynamics of keratinocytes, comprise a total number of 20 cells per 
data point and represent mean \pm s.d. of the mean. In addition, a Mann-Withney test was applied to test for statistical significance.

AFM elasticity measurements. AFM elasticity measurements were performed using a NanoWizard II AFM (JPK Instruments) mounted on top of an inverted optical microscope (Carl Zeiss AxioObserver A1). Indenter probes were prepared by gluing a single $\varnothing 10 \mu \mathrm{m}$ silica bead (Kisker Biotech) to the apex of a tipless V-shaped cantilever (NP-O, Veeco, Germany). Colloidal indenter probes were calibrated before and after each measurement. Frozen mouse skin tissue slices were attached to a microscopy slide and rehydrated in PBS for $20 \mathrm{~min}$ at room temperature. Subsequently, the indenter bead was positioned over dermal and epidermal regions as identified by light microscopy. Indentation measurements were performed by extending the closed-loop z-scanner with a constant rate of $1 \mu \mathrm{m} / \mathrm{s}$ until reaching a pre-set force of $2 \mathrm{nN}$, typically corresponded to cell indentation depths of $<1.5 \mu \mathrm{m}$. Cell elasticity values were calculated from the obtained forcedistance curves by applying a Hertzian mechanics model to the initial $500 \mathrm{~nm}$ of indentation. Elasticity measurements were performed on at least 15 different locations within the dermal or epidermal regions, using skin slices from at least three different animals per condition. The statistical significance between experimental groups was determined using a one-way ANOVA test.

\section{Conflict of Interest}

The authors declare no conflict of interest.

Acknowledgements. We are grateful to Professor Ben Wielockx (DIPP, Dresden, Germany) for help with the in vivo wound healing assay, to Professors Pierre Chambon and Daniel Metzger (IGBMC, Strasbourg, France) for the kind gift of the K14Cre mice. We thank Karin Müller-Decker (DKFZ, Heidelberg, Germany) and Peter Angel (DKFZ) for their help with the TPA induction experiments. We are extremely grateful to the animal facility of our institute (ITG, KIT) and especially to Selma Huber for their help with animal experiments. We also want to thank R. Saffrich (Department of Medicine V (Hematology, Oncology \& Rheumatology, University of Heidelberg, Heidelberg) for technical assistance in time-lapse imaging. We are grateful to Julia Gutjahr (Laboratory for Immunological and Molecular Cancer Research, Salzburg, Austria) for her help with the immunohistological pictures. We also thank Ana Guío-Carrión (Spanish National Cancer Centre, Genes Development and Disease Group, Cancer Cell Biology Programme, Madrid, Spain) for technical assistance. MT and ASB thank the German Research Foundation (Collaborative Research Center, CRC 873 B07) for support. ASB thank C. Monzel (Laboratoire Physico-Chimie, Institut Curie, Paris, France) for assistance in data analysis. iCeMS is supported by World Premier International Research Center Initiative (WPI), MEXT (Japan). EFW and LB are supported by grants from the Spanish Ministry of Economy (BFU2012-40230, and SAF2015-70857, co-funded by the ERDF-EU).

\section{Author contributions}

MS performed most of the experiments and analyzed the data. ASB performed all RICM measurements and analyzed the data and wrote the corresponding text. CMF performed the AFM measurements, analyzed the data and wrote the corresponding text. GP, KB and EH performed part of the experiments. $A D$ and TK contributed to the development of the Cd44 floxed mice. EFW, TNH and MT designed part of the experiments and analyzed the data. HP analyzed the data and participated in the writing of the manuscript. LB performed part of the experiments and contributed to the writing of the manuscript. VOR contributed to the production of the Cd44 floxed, analyzed the data and wrote the manuscript.

1. Orian-Rousseau V. CD44, a therapeutic target for metastasising tumours. Eur J Cancer 2010; 46: 1271-1277.

2. Wheatley $\mathrm{SC}$, Isacke $\mathrm{CM}$, Crossley $\mathrm{PH}$. Restricted expression of the hyaluronan receptor, CD44, during postimplantation mouse embryogenesis suggests key roles in tissue formation and patterning. Development 1993; 119: 295-306

3. Bennett KL, Jackson DG, Simon JC, Tanczos E, Peach R, Modrell B et al. CD44 isoforms containing exon $\mathrm{v} 3$ are responsible for the presentation of heparin-binding growth factor. J Cell Biol 1995; 128: 687-698.

4. Sherman L, Wainwright $D$, Ponta $H$, Herrlich $P$. A splice variant of CD44 expressed in the apical ectodermal ridge presents fibroblast growth factors to limb mesenchyme and is required for limb outgrowth. Genes Dev 1998; 12: 1058-1071.
5. Volz Y, Koschut D, Matzke-Ogi A, Dietz MS, Karathanasis C, Richert L et al. Direct binding of hepatocyte growth factor and vascular endothelial growth factor to CD44v6. Biosci Rep 2015; 35: pii: e00236.

6. Orian-Rousseau V, Chen L, Sleeman JP, Herrlich P, Ponta H. CD44 is required for two consecutive steps in HGF/c-Met signaling. Genes Dev 2002; 16: 3074-3086.

7. Matzke A, Sargsyan V, Holtmann B, Aramuni G, Asan E, Sendtner $M$ et al. Haploinsufficiency of c-Met in cd44-/ - mice identifies a collaboration of CD44 and c-Met in vivo. Mol Cell Biol 2007; 27: 8797-8806.

8. Matzke-Ogi A, Jannasch K, Shatirishvili M, Fuchs B, Chiblak S, Morton J et al. Inhibition of tumor growth and metastasis in pancreatic cancer models by interference with CD44v6 signaling. Gastroenterology 2016; 150: 513-525 e510.

9. Schmitt M, Metzger M, Gradl D, Davidson G, Orian-Rousseau V. CD44 functions in Wnt signaling by regulating LRP6 localization and activation. Cell Death Differ 2015; 22: 677-689.

10. Aruffo A, Stamenkovic I, Melnick M, Underhill CB, Seed B. CD44 is the principal cell surface receptor for hyaluronate. Cell 1990; 61: 1303-1313.

11. Orian-Rousseau V, Sleeman J. CD44 is a multidomain signaling platform that integrates extracellular matrix cues with growth factor and cytokine signals. Adv Cancer Res 2014; 123: 231-254

12. Fuchs K, Hippe A, Schmaus A, Homey B, Sleeman JP, Orian-Rousseau V. Opposing effects of high- and low-molecular weight hyaluronan on CXCL12-induced CXCR4 signaling depend on CD44. Cell Death Dis 2013; 4: e819.

13. Bourguignon $\mathrm{LY}$, Peyrollier K, Gilad E, Brightman A. Hyaluronan-CD44 interaction with neural Wiskott-Aldrich syndrome protein (N-WASP) promotes actin polymerization and ErbB2 activation leading to beta-catenin nuclear translocation, transcriptional up-regulation, and cell migration in ovarian tumor cells. J Biol Chem 2007; 282: 1265-1280.

14. Protin U, Schweighoffer T, Jochum W, Hilberg F. CD44-deficient mice develop normally with changes in subpopulations and recirculation of lymphocyte subsets. J Immunol 1999; 163 : 4917-4923.

15. Schmits R, Filmus J, Gerwin N, Senaldi G, Kiefer F, Kundig T et al. CD44 regulates hematopoietic progenitor distribution, granuloma formation, and tumorigenicity. Blood 1997; 90: 2217-2233.

16. Kaya G, Rodriguez I, Jorcano JL, Vassalli P, Stamenkovic I. Selective suppression of CD44 in keratinocytes of mice bearing an antisense CD44 transgene driven by a tissue-specific promoter disrupts hyaluronate metabolism in the skin and impairs keratinocyte proliferation. Genes Dev 1997; 11: 996-1007.

17. Olaku V, Matzke A, Mitchell C, Hasenauer S, Sakkaravarthi A, Pace G et al. c-Met recruits ICAM-1 as a coreceptor to compensate for the loss of CD44 in Cd44 null mice. Mol Biol Cell 2011; 22: 2777-2786.

18. Valluru M, Brown NJ, Cross SS, Reed MW, Staton CA. Blood vessel characterization in human dermal wound repair and scarring. Br J Dermatol 2011; 165: 221-224.

19. Fuchs E. Skin stem cells: rising to the surface. J Cell Biol 2008; 180: 273-284.

20. Yu BD, Mukhopadhyay A, Wong C. Skin and hair: models for exploring organ regeneration. Hum Mol Genet 2008; 17: R54-R59.

21. Li M, Chiba H, Warot X, Messaddeq N, Gerard C, Chambon P et al. RXR-alpha ablation in skin keratinocytes results in alopecia and epidermal alterations. Development 2001; 128 : 675-688.

22. Fuchs E. Epidermal differentiation: the bare essentials. J Cell Biol 1990; 111: 2807-2814.

23. Moll R, Divo M, Langbein L. The human keratins: biology and pathology. Histochem Cell Biol 2008; 129: 705-733.

24. Wojcik SM, Longley MA, Roop DR. Discovery of a novel murine keratin 6 (K6) isoform explains the absence of hair and nail defects in mice deficient for $\mathrm{K} 6 \mathrm{a}$ and $\mathrm{K} 6 \mathrm{~b}$. J Cell Biol 2001; 154: 619-630.

25. Hildenbrand M, Rhiemeier V, Hartenstein B, Lahrmann B, Grabe N, Angel P et al. Impaired skin regeneration and remodeling after cutaneous injury and chemically induced hyperplasia in taps-transgenic mice. J Invest Dermatol 2010; 130: 1922-1930.

26. Michalik L, Desvergne B, Tan NS, Basu-Modak S, Escher P, Rieusset J et al. Impaired skin wound healing in peroxisome proliferator-activated receptor (PPAR)alpha and PPARbeta mutant mice. J Cell Biol 2001; 154: 799-814.

27. Fuchs $\mathrm{E}$, Green $\mathrm{H}$. Changes in keratin gene expression during terminal differentiation of the keratinocyte. Cell 1980; 19: 1033-1042.

28. Dale BA, Holbrook KA, Kimball JR, Hoff M, Sun TT. Expression of epidermal keratins and filaggrin during human fetal skin development. J Cell Biol 1985; 101: 1257-1269.

29. Sandilands $A$, Sutherland $C$, Irvine $A D$, McLean WH. Filaggrin in the frontline: role in skin barrier function and disease. J Cell Sci 2009; 122: 1285-1294.

30. Mehrel T, Hohl D, Rothnagel JA, Longley MA, Bundman D, Cheng C et al. Identification of a major keratinocyte cell envelope protein, loricrin. Cell 1990; 61: 1103-1112.

31. Schmuth M, Fluhr JW, Crumrine DC, Uchida Y, Hachem JP, Behne M et al. Structural and functional consequences of loricrin mutations in human loricrin keratoderma (Vohwinkel syndrome with ichthyosis). J Invest Dermatol 2004; 122: 909-922.

32. Stern R, Maibach HI. Hyaluronan in skin: aspects of aging and its pharmacologic modulation Clin Dermatol 2008; 26: 106-122.

33. Hiraga $\mathrm{T}$, Ito $\mathrm{S}$, Nakamura $\mathrm{H}$. Cancer stem-like cell marker $\mathrm{CD} 44$ promotes bone metastases by enhancing tumorigenicity, cell motility, and hyaluronan production. Cancer Res 2013; 73: $4112-4122$.

34. Wiranowska M, Ladd S, Moscinski LC, Hill B, Haller E, Mikecz $\mathrm{K}$ et al. Modulation of hyaluronan production by CD44 positive glioma cells. Int J Cancer 2010; 127: 532-542. 
35. Kaindl T, Rieger H, Kaschel LM, Engel U, Schmaus A, Sleeman J et al. Spatio-temporal patterns of pancreatic cancer cells expressing CD44 isoforms on supported membranes displaying hyaluronic acid oligomers arrays. PLoS One 2012; 7: e42991.

36. Betz T, Lenz M, Joanny JF, Sykes C. ATP-dependent mechanics of red blood cells. Proc Natl Acad Sci USA 2009; 106: 15320-15325.

37. Gov NS, Safran SA. Red blood cell membrane fluctuations and shape controlled by ATP-induced cytoskeletal defects. Biophys J 2005; 88: 1859-1874.

38. Burk AS, Monzel C, Yoshikawa HY, Wuchter P, Saffrich R, Eckstein V et al. Quantifying adhesion mechanisms and dynamics of human hematopoietic stem and progenitor cells. Sci Rep 2015; 5: 9370.

39. Achterberg VF, Buscemi L, Diekmann H, Smith-Clerc J, Schwengler H, Meister JJ et al. The nano-scale mechanical properties of the extracellular matrix regulate dermal fibroblast function. J Invest Dermatol 2014; 134: 1862-1872.

40. Engler AJ, Rehfeldt F, Sen S, Discher DE. Microtissue elasticity: measurements by atomic force microscopy and its influence on cell differentiation. Methods Cell Biol 2007; 83: 521-545.

41. Miller DL, Ortega S, Bashayan O, Basch R, Basilico C. Compensation by fibroblast growth factor 1 (FGF1) does not account for the mild phenotypic defects observed in FGF2 null mice. Mol Cell Biol 2000; 20: 2260-2268.

42. Sturm J, Keese M, Zhang H, Bonninghoff R, Magdeburg R, Vajkoczy $P$ et al. Liver regeneration in FGF-2-deficient mice: VEGF acts as potential functional substitute for FGF-2. Liver Int 2004; 24: 161-168.

43. Harada A, Oguchi K, Okabe S, Kuno J, Terada S, Ohshima T et al. Altered microtubule organization in small-calibre axons of mice lacking tau protein. Nature 1994; 369: 488-491.

44. Wainwright DM. Growth Factor Presentation by CD44 Variant Proteins 1998, Imperia College of Science, Technology and Medicine: London. PhD Thesis.

45. Nedvetzki S, Gonen E, Assayag N, Reich R, Williams RO, Thurmond RL et al. RHAMM, a receptor for hyaluronan-mediated motility, compensates for CD44 in inflamed CD44knockout mice: a different interpretation of redundancy. Proc Natl Acad Sci USA 2004; 101 : 18081-18086.

46. Durchdewald M, Guinea-Viniegra J, Haag D, Riehl A, Lichter P, Hahn M et al. Podoplanin is a novel fos target gene in skin carcinogenesis. Cancer Res 2008; 68: 6877-6883.

47. Wurm S, Zhang J, Guinea-Viniegra J, Garcia F, Munoz J, Bakiri L et al. Terminal epidermal differentiation is regulated by the interaction of Fra-2/AP-1 with Ezh2 and ERK1/2. Genes Dev 2015; 29: 144-156.

48. Zenz R, Scheuch $H$, Martin $P$, Frank $C$, Eferl R, Kenner $L$ et al. c-Jun regulates eyelid closure and skin tumor development through EGFR signaling. Dev Cell 2003; 4: 879-889.

49. Hofmann M, Rudy W, Gunthert U, Zimmer SG, Zawadzki V, Zoller M et al. A link between ras and metastatic behavior of tumor cells: ras induces CD44 promoter activity and leads to lowlevel expression of metastasis- specific variants of CD44 in CREF cells. Cancer Res 1993; 53: $1516-1521$.

50. Rilla K, Lammi MJ, Sironen R, Torronen K, Luukkonen M, Hascall VC et al. Changed lamellipodial extension, adhesion plaques and migration in epidermal keratinocytes containing constitutively expressed sense and antisense hyaluronan synthase 2 (Has2) genes. J Cell Sci 2002; 115: 3633-3643.
51. Evans ND, Oreffo RO, Healy E, Thurner PJ, Man YH. Epithelial mechanobiology, skin wound healing, and the stem cell niche. J Mech Behav Biomed Mater 2013; 28: 397-409.

52. Wang Y, Wang G, Luo X, Qu J, Tang C. Substrate stiffness regulates the proliferation, migration, and differentiation of epidermal cells. Burns 2012; 38: 414-420.

53. Cao G, Savani RC, Fehrenbach M, Lyons C, Zhang L, Coukos G et al. Involvement of endothelial CD44 during in vivo angiogenesis. Am J Pathol 2006; 169: 325-336.

54. Bourguignon LY, Ramez M, Gilad E, Singleton PA, Man MQ, Crumrine DA et al. Hyaluronan-CD44 interaction stimulates keratinocyte differentiation, lamellar body formation/secretion, and permeability barrier homeostasis. J Invest Dermatol 2006; 126 : 1356-1365.

55. Flynn KM, Michaud M, Canosa S, Madri JA. CD44 regulates vascular endothelial barrier integrity via a PECAM-1 dependent mechanism. Angiogenesis 2013; 16: 689-705.

56. Sibilia M, Wagner EF. Strain-dependent epithelial defects in mice lacking the EGF receptor. Science 1995; 269: 234-238.

57. Crooke ST. Antisense strategies. Curr Mol Med 2004; 4: 465-487.

58. Khaldoyanidi S, Karakhanova S, Sleeman J, Herrlich P, Ponta H. CD44 variant-specific antibodies trigger hemopoiesis by selective release of cytokines from bone marrow macrophages. Blood 2002; 99: 3955-3961.

59. Biase FH, Franco MM, Goulart LR, Antunes RC. Protocol for extraction of genomic DNA from swine solid tissues. Genet Mol Biol 2002; 25: 313-315.

60. Sackmann E. Supported membranes: scientific and practical applications. Science 1996; 271: $43-48$.

61. Monzel C, Fenz SF, Merkel R, Sengupta K. Probing biomembrane dynamics by dualwavelength reflection interference contrast microscopy. Chemphyschem 2009; 10: 2828-2838.

62. Coelho Neto J, Agero U, Gazzinelli RT, Mesquita ON. Measuring optical and mechanical properties of a living cell with defocusing microscopy. Biophys J 2006; 91: 1108-1115. published by Nature Publishing Group. This work is licensed under a Creative Commons Attribution 4.0 International License. The images or other third party material in this article are included in the article's Creative Commons license, unless indicated otherwise in the credit line; if the material is not included under the Creative Commons license, users will need to obtain permission from the license holder to reproduce the material. To view a copy of this license, visit http://creativecommons.org/licenses/by/4.0/

(C) The Author(s) 2016

Supplementary Information accompanies this paper on Cell Death and Disease website (http://www.nature.com/cddis) 